\title{
JÓVENES Y JUVENTUD EN LOS ESPACIOS IBÉRICOS DURANTE EL ANTIGUO RÉGIMEN. VIDAS EN CONSTRUCCIÓN
}

\section{José Pablo Blanco Carrasco, Máximo García Fernández y Fernanda Olival (COORDS.)}

\author{
Lisboa, 2019, Ediciones Colibrí, 218 páginas
}

ISBN: 978-98-9689-722-2

El libro que aquí se reseña, coordinado por José Pablo Blanco de la universidad de Extremadura, Máximo García de Valladolid y Fernanda Olivar de Évora, sienta las bases de una historia de los ciclos vitales aun por escribir. Enfocada mayormente en la infancia, sobre todo los huérfanos y las instituciones que los acogieron, y en la vejez, períodos ambos caracterizados por unos marcos, tanto biológicos como culturales, más exactos. El estudio de la juventud se ha ido abriendo paso en los discursos históricos durante los últimos años, esta tardanza hay que buscarla principalmente en la inexactitud de las fronteras de referida edad y, por ende, en la dificultad de su estudio.

No obstante, y como bien aseveran los coordinadores en la presentación, no estamos ante un campo desolado, puesto que existen publicaciones, y con ritmo ascendente, preocupadas por las vivencias de estos jóvenes en el pasado, por el papel que jugaron como parte de la familia y por su incorporación a la sociedad a través del trabajo y de una unión matrimonial que marcaría un hito en el propio ciclo del individuo poniendo fin a la patria potestad.

La obra reúne un total de siete capítulos organizados en tres grandes apartados: desigualdad y desobediencia; jóvenes en familia; ciclo vital y civilización juvenil, que pretenden, y sobradamente consiguen, estudiar un colectivo social en una estación limítrofe entre la puerilidad y la adultez. El momento en el que se sentaban las bases para el resto de sus vidas en un estrato determinado, todo ello teniendo como escenario la península Ibérica, permitiendo, por consiguiente, un conocimiento a partir de la historia comparada.

Los dos primeros capítulos abordarán como tema principal el matrimonio, uno de los momentos más delicados en la trayectoria no sólo del individuo sino también de las respectivas familias y de la sociedad en su sentido más amplio. Fue precisamente, esta preocupación la que llevó a las instituciones civiles y eclesiásticas a desarrollar una amplia regulación al respecto. Esta es estudiada por $\mathrm{M}^{\mathrm{a}}$ Ángeles Sobaler en el primer capítulo del 
libro. En él realiza un recorrido por la legislación castellana desde el medievo, con el Fuero Realy las Partidas, hasta finales del siglo XVIII, que buscó solventar el problema de los enlaces clandestinos y desiguales, toda vez que subyace una voluntad individual de los jóvenes en este tipo de actitudes desobedientes ante unas estrategias familiares concretas. Sin embargo, las directrices seguidas por el derecho canónico difirieron en ciertos aspectos del civil, en un proceso que desembocó en la célebre Pragmática de 1776 que, si bien reafirmaba el poder los padres o los pertinentes familiares, también puso límites a dicha autoridad: en última instancia el hijo debía participar en la decisión que se iba a tomar.

Por otra parte, el profesor Blanco Carrasco analiza los discursos morales publicados durante el siglo XVIII que marcaron los criterios rectores de las relaciones paternofiliales fundamentadas en el respeto y, sobre todo, en la obediencia. Frente a esto, se señalan casos donde dicha premisa estuvo lejos de cumplirse, destacando, de nuevo, actuaciones desobedientes de los jóvenes hacia sus progenitores y que van a estar presentes en momentos de transición doméstica, esto es, cuando la potestad paterna finalizó tras la toma de estado con la consiguiente salida del hogar. Sin embargo, no fue este el único momento proclive hacia referidas actuaciones, también lo fue cuando, liberado ya de esa potestad, el hijo tuvo que encargarse de sus progenitores ancianos. En este último caso, la moral comunitaria jugó un papel relevante como grupo de presión hacia unos vástagos que debían cumplir con su cometido. No obstante, como afirma el autor, detrás de estas ayudas intergeneracionales existieron intereses puramente económicos. Ante estas más que posibles situaciones, la tratadística moderna se manifestó aconsejando a los padres retener los bienes y la hacienda particular hasta el momento de su defunción, pues un reparto anterior podría causar el abandono, ya que la gran mayoría de jóvenes comenzaron sus vidas independientes gracias a la ayuda económica de los progenitores. Pero no se destacan exclusivamente estos tratados como medio de acercamiento. La documentación notarial, las fuentes fiscales, especialmente para el mundo rural, o los pleitos son puestos en valor para la investigación de esta insubordinación juvenil.

El segundo bloque trata al joven como parte de la familia en la que se integró desde su nacimiento. Para ello, Francisco Javier Lorenzo aborda el tema de los huérfanos en la Salamanca del siglo XVI recalcando la importancia de los documentos de curaduría y tutoría con la pretensión de conocer cómo fue la gestión de los bienes realizada por los encargados de los menores, y si en ella se perciben diferencias entre sexos. Advierte, sin embargo, las carencias de la propia tipología, con ausencias en ocasiones sobre la edad del joven, la profesión del padre o la, a veces, escasa pulcritud con la que se inscribieron ciertos gastos. 
Con respecto a la relación entre los curadores y los menores, el autor da a conocer como esta fue inusual, así como tampoco duradera ni positiva. Se caracterizaron por una convivencia escasa, a excepción de los periodos de enfermedad. Situación que se salvó con la entrada de los menores en el mundo laboral, bien como criadas o como aprendices en un taller artesanal, o habitando con familiares directos que percibirían un ingreso por parte del curador. Entre las cuantías, se observa la predominancia de la vestimenta, el calzado y la alimentación, seguido de unos gastos en educación y/o formación, que al igual que los destinados al ocio, estuvieron restringidos a las mujeres.

Por su parte, Antonio Irigoyen indaga en las trayectorias de aquellos jóvenes que decidieron, bien por voluntad propia bien por estrategia familiar, comenzar la carrera eclesiástica. Esta elección se contrapuso a veces, especialmente cuando se trataba de un hijo único, a los intereses de los padres cuyas expectativas se dirigían a perpetuar el negocio o a asentar o aumentar una situación económica determinada. De ello se extrae la importancia de incluir en el análisis histórico la vocación como signo de esa plasmación de la voluntad del individuo. En el mismo estudio, el autor destaca la importancia de los pajes y criados de los obispos. Jóvenes que integraron con gran asiduidad los hogares de los prelados durante la modernidad con el fin de iniciar y prosperar en la jerarquía eclesiástica. Enfocando la mirada en las distintas tipologías de pajes, esta panorámica se vincula con el ejercicio de la caridad, por un lado, y, por otro, con la creación de pequeñas cortes propias de los palacios episcopales, destinadas a la ayuda en las tareas del cargo.

El tercer y último de los bloques del libro está compuesto por tres capítulos. En el primero de ellos, Fernanda Olival presenta los requisitos etarios portugueses necesarios para comenzar a desempeñar actividades profesionales, contraer matrimonio, obtener dignidades regias, entrar en Órdenes Militares o iniciar la carrera eclesiástica. Así, observando las diversas divisorias, establece como además de los 25 años, que marcaron el inicio de la mayoría de edad, existieron otras delimitaciones como los siete, a partir del cual las capas sociales más bajas se integraron en determinadas labores; los 12 para la otorgación de la moradia; o, para ser familiar del Santo Oficio, una edad que varió durante la Edad Moderna desde los 15 hasta los 20 ya en el siglo XVIII.

Por su parte, Juan Manuel Bartolomé y Francisco Javier Lagartos estudian el grupo de los criados en la provincia de León desde inicios de la centuria dieciochesca hasta mediados del XIX, contraponiendo el mundo rural, a través de la comarca de Sahugún, y el mundo urbano con la propia ciudad de León, puesto que el organigrama social de ambos espacios determinó las características del grupo de criados, destinados en unos casos a la 
labor agrícola y, en otros, a la función doméstica. Con respecto a sus edades, la media de edad entre los hombres será menor, predominando el life-cycle servant, frente a una más elevada entre las mujeres proclives al life-time servant. Además, inquiere sobre el acceso de este sector a los productos especialmente en almonedas y las austeras condiciones de vida proporcionadas por sus amos.

El capítulo que cierra el libro corre a cargo de Máximo García. En él, el autor expone los distintos modelos de la juventud masculina. Partiendo de distintos ejemplos proporcionados por las historias y literatura de la época, repasa desde la picaresca, personificada por el Lazarillo del Manzanares, hasta el ascenso a los altares de San Juan de la Cruz, no sin atender a otras formas como la planteada a través de Antón Zotes y Ventura Pérez asociados a unas trayectorias donde la educación y la formación artesanal jugaron un extraordinario papel. Otra de las situaciones será la referente al carácter alborotador que tuvieron algunos jóvenes, hecho que propició un deseo de control por parte de las autoridades pertinentes. Sin embargo, si cabe destacar algo son las formas de un camino 'decente', alcanzado mediante el trabajo o la formación, cada vez más relevante en el ideario colectivo. Todo ello tomando como referencia la información inserta en los pleitos.

En definitiva, la producción histórica sobre los ciclos vitales suma una obra más de obligada consulta para todos aquellos que pretendan acercarse al mundo de los jóvenes en la historia. A una juventud que, lejos de ostentar un papel secundario, fue poseedora de una voluntad individual que le llevó en ocasiones a plantear problemas internos y externos del grupo doméstico, pues en última instancia representaba el cambio hacia nuevas formas de relación social.

Francisco Hidalgo Fernández

Universidad de Málaga 